\title{
Differentiation Inducer
}

National Cancer Institute

\section{Source}

National Cancer Institute. Differentiation Inducer. NCI Thesaurus. Code C1934.

An agent that induces the differentiation or maturation of cells, specifically neoplastic cells, resulting in decreases in tumor growth and metastasis. (NCI04) 